\title{
Rare KMT2A-ELL and Novel ZNF56-KMT2A Fusion Genes in Pediatric T-cell Acute Lymphoblastic Leukemia
}

\author{
IOANNIS PANAGOPOULOS ${ }^{1}$, KRISTIN ANDERSEN $^{1}$, MARTINE EILERT-OLSEN $^{1}$, \\ ANNE GRO ROGNLIEN ${ }^{2}$, MONICA CHENG MUNTHE-KAAS ${ }^{2}$, FRANCESCA MICCI ${ }^{1}$ and SVERRE HEIM ${ }^{1,3}$ \\ ${ }^{1}$ Section for Cancer Cytogenetics, Institute for Cancer Genetics and Informatics, \\ The Norwegian Radium Hospital, Oslo University Hospital, Oslo, Norway; \\ ${ }^{2}$ Department of Pediatric Hematology and Oncology, Oslo University Hospital Rikshospitalet, Oslo, Norway; \\ ${ }^{3}$ Institute of Clinical Medicine, Faculty of Medicine, University of Oslo, Oslo, Norway
}

\begin{abstract}
Background/Aim: Previous reports have associated the KMT2A-ELL fusion gene, generated by $t(11 ; 19)(q 23 ; p 13.1)$, with acute myeloid leukemia $(A M L)$. We herein report a KMT2A-ELL and a novel ZNF56-KMT2A fusion genes in a pediatric T-lineage acute lymphoblastic leukemia (T-ALL). Materials and Methods: Genetic investigations were performed on bone marrow of a 13-year-old boy diagnosed with T-ALL. Results: A KMT2A-ELL and a novel ZNF56-KMT2A fusion genes were generated on der(11)t(11;19)(q23;p13.1) and $\operatorname{der}(19) t(11 ; 19)(q 23 ; p 13.1)$, respectively. Exon 20 of KMT2A fused to exon 2 of ELL in KMT2A-ELL chimeric transcript whereas exon 1 of ZNF56 fused to exon 21 of KMT2A in ZNF56-KMT2A transcript. A literature search revealed four more T-ALL patients carrying a KMT2A-ELL fusion. All of them were males aged 11, 11, 17, and 20 years. Conclusion: KMT2AELL fusion is a rare recurrent genetic event in T-ALL with uncertain prognostic implications. The frequency and impact of ZNF56-KMT2A in T-ALL are unknown.
\end{abstract}

The chromosomal translocation $\mathrm{t}(11 ; 19)(\mathrm{q} 23 ; \mathrm{p} 13)$ has been reported in both acute myeloid leukemia (AML) and acute lymphoblastic leukemia (ALL) (1). Early cytogenetic studies did not discriminate between different breakpoints within band 19 p13 in cases with $t(11 ; 19)(q 23 ; p 13)$, but it later became clear that two breakpoint clusters existed within band 19p13

This article is freely accessible online.

Correspondence to: Ioannis Panagopoulos, Section for Cancer Cytogenetics, Institute for Cancer Genetics and Informatics, The Norwegian Radium Hospital, Oslo University Hospital, P.O.Box 4953 Nydalen, NO-0424 Oslo, Norway. Tel: +47 22934424, email: ioannis.panagopoulos@rr-research.no

Key Words: T-cell acute lymphoblastic leukemia, pediatric, fusion gene, KMT2A, ELL, ZNF56, KMT2A-ELL ZNF56-KMT2A, RNAsequencing. which could be distinguished by fluorescence in situ hybridization (FISH) $(2,3)$. Breakpoints within sub-band 19 p13.3 have been found in both ALL (primarily in infants and children) and AML. The translocation $\mathrm{t}(11 ; 19)(\mathrm{q} 23 ; \mathrm{p} 13.3)$ leads to fusion of the histone-lysine $\mathrm{N}$-methyltransferase $2 \mathrm{~A}$ (KMT2A; also known as myeloid/lymphoid or mixed lineage leukemia, $M L L$ ) gene in 11q23 with the MLLT1 super elongation complex subunit MLLT1 gene (also known as ENL, LTG19, and YEATS1) in 19p13.3 generating a KMT2A-MLLT1 fusion (1, 4-6). Two more KMT2A-fusion genes have been reported with relevance to sub-band 19p13.3: a fusion of KMT2A with the SH3 domain containing GRB2 like 1, endophilin A2 (SH3GL1) gene [translocation $\mathrm{t}(11 ; 19)(\mathrm{q} 23 ; \mathrm{p} 13.3)]$ in a case of childhood AML (7), and fusion of KMT2A with the vav guanine nucleotide exchange factor 1 (VAVI) gene at $19 \mathrm{p} 13.3$ in a pediatric AML (8). In sub-band 19p13.2, a recurrent fusion of $K M T 2 A$ with the myosin IF $(M Y O 1 F)$ gene [translocation $\mathrm{t}(11 ; 19)(\mathrm{q} 23 ; \mathrm{p} 13.2)]$ has been detected in infant and pediatric AML (8-10).

Breakpoints within sub-band $19 \mathrm{p} 13.1$ were believed to be exclusively found in AML, where the translocation $\mathrm{t}(11 ; 19)(\mathrm{q} 23 ; \mathrm{p} 13.1)$ resulted in fusion of $K M T 2 A$ with the elongation factor for RNA polymerase II (ELL) gene (11). The overall frequency of ELL as KMT2A's translocation partner was found to be $4.1 \%$ and KMT2A-ELL fusion was found in $15 \%$ of infant AML, $7 \%$ of pediatric AML, and $12 \%$ of adult AML (8). Recently, KMT2A-ELL fusion gene was detected also in two bi-phenotypic leukemias and in four pediatric T-ALL patients (12-15). Because of the rarity of T-ALL carrying a KMT2A-ELL fusion gene, we report here the genetic and clinical features of a pediatric T-ALL with an unbalanced chromosome translocation between the chromosome bands 11q23 and 19p13 resulting in two fusion genes: a KMT2A-ELL in which the 5'-part of KMT2A is fused to $E L L$, and a novel fusion gene in which the 5'-part of the zinc finger protein 56 gene (ZNF56) is fused to the 3'-part of KMT2A. 
Table I. BAC probes used for fluorescence in situ hybridization (FISH) experiments.

\begin{tabular}{lccccc}
\hline BAC clones & Accession number & Chromosome mapping & Targeted gene & Position on GRCh38/hg38 assembly & Labelling \\
\hline RP11-770J1 & AP001267.4 & $11 \mathrm{q} 23.3$ & KMT2A & chr11:118374563-118524770 & Green \\
RP11-861M13 & AP000941.6 & $11 \mathrm{q} 23.3$ & KMT2A & chr11:118524771-118608821 & Green \\
CH17-258D2 & Not avaliable & $19 \mathrm{p} 13.11$ & $E L L$ & chr19:18213782-18431838 & Red \\
CH17-343F16 & Not avaliable & $19 \mathrm{p} 13.11$ & $E L L$ & chr19:18318183-18514614 & Red \\
CH17-413G9 & Not avaliable & $19 \mathrm{p} 13.11$ & ELL & chr19:18568795-18764997 & Red \\
CH17-338M17 & Not avaliable & $19 \mathrm{p} 13.11$ & $E L L$ & chr19:18611693-18826326 & Red \\
\hline
\end{tabular}

\section{Materials and Methods}

Ethics statement. The study was approved by the regional ethics committee (Regional komité for medisinsk forskningsetikk Sør-Øst, Norge, http://helseforskning.etikkom.no; 2010/1389/REK sør-øst A), and written informed consent was obtained from the patient's parents. All patient information has been anonymized.

Case report. A previously healthy thirteen-year-old boy presented with lethargy, pan-cytopenia, hepatosplenomegaly, and pathological glandules on both sides of the neck. He was diagnosed with T-ALL and treated according to the Nordic Society for Pediatric Hematology and Oncology Protocol ALL2008 (16). Because of T-lineage ALL, he started high risk induction therapy. Due to cytogenetic detection of the $K M T 2 A$ rearrangement (see below) and inadequate therapy response, he was stratified to first to high intensity treatment and then stem cell transplantation in first remission. His pre-transplantation treatment was complicated with severe toxicities. A stem cell transplantation with a 10/10 matched unrelated donor was performed after five blocks and conditioning with total body irradiation and etoposide. He had a skin graft vs host disease grad 1-2, otherwise it was an uncomplicated transplantation. Bone marrow evaluation before conditioning and on day 28 post transplantation showed detectable residual disease but below quantifiable level. Bone marrow 3 months post transplantation showed no residual disease, and he is still in remission 20 months post transplantation.

G-banding and fluorescence in situ hybridization (FISH) analyses. Bone marrow cells were short-term cultured and analyzed cytogenetically as previously described (17). FISH analyses of bone marrow interphase nuclei and metaphase spreads were performed with the Cytocell KMT2A (MLL) break-apart probe (Cytocell, Oxford Gene Technology, Begbroke, Oxfordshire, UK).

For the detection of KMT2A-ELL fusion gene a home-made double fusion FISH probe was used. The BAC probes were purchased from BACPAC Resource Center which is operated by BACPAC Genomics, Emeryville, CA (https://bacpacresources.org/) (Table I). The probes for $K M T 2 A$ were labelled with fluorescein-12-dCTP (PerkinElmer, Boston, MA, USA) in order to obtain green signals. The probes for ELL were labelled with Texas Red-5-dCTP (PerkinElmer, Boston, MA, USA) in order to obtain a red signal. Detailed information on the FISH procedure was given elsewhere $(18,19)$. Fluorescent signals were captured and analyzed using the CytoVision system (Leica Biosystems, Newcastle, UK).

RNA isolation and complementary DNA (cDNA) synthesis. Total RNA was extracted from the patient's bone marrow at diagnosis using the miRNeasy Mini Kit (Qiagen, Hilden, Germany). The concentration and purity of RNA were measured with the QIAxpert microfluidic UV/VIS spectrophotometer (Qiagen). The quality of RNA, in terms of RNA Integrity Number (RIN), was assessed using the Agilent 2100 bioanalyzer (Agilent, Santa Clara, CA, USA) (20). The RIN was found to be 8.9. For the synthesis of complementary DNA (cDNA), one $\mu \mathrm{g}$ of total RNA was reverse transcribed using iScript Advanced cDNA Synthesis Kit for RT-qPCR according to the manufacturer's instructions (Bio-Rad, Hercules, CA, USA).

RNA sequencing. High-throughput paired-end RNA-sequencing was performed at the Genomics Core Facility, Norwegian Radium Hospital, Oslo University Hospital (http://genomics.no/oslo/) and 106 million 75 bp-reads were generated. The FASTQC software was used for quality control of the raw sequence data (https://www.bioinformatics.babraham.ac.uk/projects/fastqc/). The software FusionCatcher was used to find fusion transcripts $(21,22)$.

PCR analyses. The primers used for PCR amplification and Sanger sequencing are listed in Table II. For reverse transcription-polymerase chain reaction (RT-PCR) and cycle Sanger sequencing, the BigDye Direct Cycle Sequencing Kit was used (ThermoFisher Scientific, Waltham, MA, USA) according to the company's recommendations. As template, cDNA corresponding to $20 \mathrm{ng}$ total RNA was used. For the detection of KMT2A-ELL chimeric cDNA fragments, the primer sets were M13ForMLL5580F1/M13RevELL438R1 and M13ForMLL-5589F1/M13Rev-ELL-415R1. For the detection of ZNF56$K M T 2 A$ chimeric cDNA fragments, the primer sets were M13ForZNF56-249F1/M13RevMLL5867R1 and M13ForZNF56277F1/M13RevMLL5815R1.

Sequence analyses were performed on the Applied Biosystems SeqStudio Genetic Analyzer system (ThermoFisher Scientific). The basic local alignment search tool (BLAST) software (https://blast.ncbi.nlm.nih.gov/Blast.cgi) was used for computer analysis of sequence data (23). The BLAT alignment tool and the human genome browser at UCSC were also used to map the sequences on the Human GRCh37/hg19 assembly $(24,25)$.

\section{Results}

G-banding analysis of bone marrow cells at diagnosis yielded the karyotype 46,XY,der(11)t(11;19)(q23;p13),del(12)(p11), $\operatorname{der}(15) ? \mathrm{t}(15 ; 19)(\mathrm{q} 26 ; \mathrm{q} 11), \operatorname{der}(19) \mathrm{t}(11 ; 19)(\mathrm{q} 23 ; \mathrm{p} 13) \operatorname{del}(19)$ (q11) [10]/46,XY[2] (Figure 1).

Interphase FISH with the KMT2A break-apart probe showed a normal (yellow) as well as split (separated red and 
Table II. Primers used for PCR amplification and Sanger sequencing analyses. The M13 forward and reverse primer sequences are in bold and italics.

\begin{tabular}{|c|c|c|c|c|}
\hline Name & Sequence $\left(5^{\prime}->3^{\prime}\right)$ & Position & $\begin{array}{l}\text { Reference } \\
\text { sequence }\end{array}$ & Gene \\
\hline M13For-MLL-5580F1 & TGTAAAACGACGGCCAGT-AGGAGTCGAGAAGACAGTCCAGAGC & $5580-5604$ & NM_005933.3 & KMT2A \\
\hline M13For-MLL-5589F1 & TGTAAAACGACGGCCAGT-GAAGACAGTCCAGAGCTGAACCCA & $5589-5612$ & NM_005933.3 & KMT2A \\
\hline M13Rev-MLL-5815R1 & CAGGAAACAGCTATGACC-AGCTGCTTGCCCCTGATCACAG & $5815-5794$ & NM_005933.3 & KMT2A \\
\hline M13Rev-MLL-5867R1 & CAGGAAACAGCTATGACC-TGTGAGACAGCAACCCACGGTG & $5867-5846$ & NM_005933.3 & KMT2A \\
\hline M13Rev-ELL-438R1 & 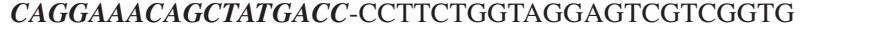 & $460-438$ & NM_006532.3 & $E L L$ \\
\hline M13Rev-ELL-415R1 & 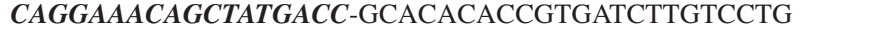 & $437-415$ & NM_006532.3 & ELL \\
\hline M13For-ZNF56-277F1 & 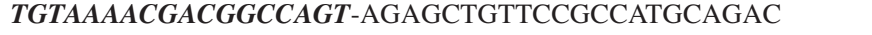 & $277-298$ & NM_001355194.1 & ZNF56 \\
\hline M13For-ZNF56-249F1 & TGTAAAACGACGGCCAGT-ACCTTCAGCCTCGCTCCTCCAT & $249-270$ & NM_001355194.1 & ZNF56 \\
\hline
\end{tabular}

green) signals of the probe in 183 out of 200 examined nuclei. On metaphase spreads the proximal part of the KMT2A-probe (green signal) was located on $\operatorname{der}(11) \mathrm{t}(11 ; 19)(\mathrm{q} 23 ; \mathrm{p} 13)$, while the distal part (red signal) was seen on $\operatorname{der}(19) \operatorname{del}(19)$ (q11)t(11;19)(23;p13) (data not shown).

Interphase FISH with the home-made KMT2A-ELL double fusion probe (Figures 2A-D) showed a yellow fusion signal, a red ELL signal and two KMT2A signals in interphase nuclei (Figure 2E). On metaphase spreads the yellow signal was detected on $\operatorname{der}(11) \mathrm{t}(11 ; 19)(\mathrm{q} 23 ; \mathrm{p} 13)$, the red signal on normal chromosome 19, a green signal on normal chromosome 11, and a green signal on $\operatorname{der}(19) \operatorname{del}(19)(\mathrm{q} 11) \mathrm{t}(11 ; 19)(23 ; \mathrm{p} 13)$ (Figure 2F).

The FusionCatcher software detected an in-frame KMT2AELL fusion transcript in which exon 20 of KMT2A (nt 5678 in sequence with accession numbers NM_005933.3) fused to exon 2 of ELL (nt 208 in sequence with accession number NM_006532.3) (ACAGTGTGCGTTATGTTTGACTTATG GTGATGACAGTGCTAAT*GATTCTGTTTCACTGAGGCC ATCTATCCGATTTCAAGGAAGCC). A ZNF56-KMT2A fusion transcript was also found in which the untranslated exon 1 of the ZNF56 gene from 19p13.11 (nt 428 in sequence with accession number NM_001355194.1) fused to exon 21 of KMT2A (nt 5679 in sequence with accession numbers NM_005933.3) (CCGCATCCCCCAACGTGCTGGCTTCCT GACTTCCAAAGTTGCG*GATGCTGGTCGTTTACTATAT ATTGGCCAAAATGAGTGGACAC).

RT-PCR and cycle Sanger sequencing confirmed the results obtained by RNA sequencing/FusionCatcher analysis (Figure 3).

\section{Discussion}

The KMT2A gene fuses in acute leukemias with more than 100 different genes coding for structurally heterogeneous proteins (8). Most breakpoints occur in the major breakpoint cluster region of KMT2A which spans from exon 7 to exon $13(8,26)$ (or exon 8 to 14 based on the sequence reported by Nilson et al. (27)). The exact breakpoint position in the major breakpoint cluster region of KMT2A influences the structure of plant homeodomains (PHD) 1-3 and correlates with clinical outcome in acute leukemias $(8,26,28,29)$. Breakpoints in intron 10 [listed as intron 11 in the references $(8,26,28,29)]$ are associated with worse prognosis whereas breakpoints within $K M T 2 A$ introns 8 and 9 [introns 9 and 10 in references $(8,26,28,29)]$ are associated with better clinical outcomes $(8,26,28-30)$. Recently, a minor breakpoint cluster region (less than $1 \%$ incidence) was detected between intron 18 and exon 23 of KMT2A, which is what we detected in our patient $(8,30)$ [in the study of (30)], the minor breakpoint cluster region is given between intron 19 and exon 24). The minor breakpoint cluster region is usually associated with KMT2A-USP2 and KMT2A-USP8 fusions (30), but it has also been reported in four T-ALL patients with KMT2A-AFDN fusion gene ( $A F D N$ maps in 6q27 and is also known as AF6 and MLLT4) (8).

The fusion genes with breakpoints in the minor breakpoint cluster region of KMT2A code for KMT2A-fusion proteins which contain intact PHD1-3 and bromodomain (BD) regions of KMT2A (30). Although the exact role of an intact PHD1-3 region in the fusion proteins is still unclear, it may be important (30). PHD1 was shown to play a role in the stability of the Nterminal part of KMT2A through interaction of PHD1 with PHD4 $(31,32)$. PHD2 was found to be an E3 ubiquitin ligase in the presence of the E2-conjugating enzyme CDC34, and mutation of PHD2 was shown to stabilize the KMT2A protein and increase its transactivation ability (33). PHD3 was reported to interact with peptidylprolyl isomerase $\mathrm{E}$ (cyclophilin $\mathrm{E}$ ) and binds to histone $\mathrm{H} 3 \mathrm{~K} 4 \mathrm{me} 3(31,34)$. Furthermore, in vitro experiments showed that the presence of the PHD regions in KMT2A-MLLT3 fusion proteins influenced their function and inhibited KMT2A-MLLT3 transformation of mouse bone marrow cells (35). Loss of PHD3 was necessary for KMT2AMLLT1-induced hematopoietic stem cell immortalization (36).

The ELL gene (19p13.1) encodes a nuclear protein (accession number NP_006523) which regulates the activity of the RNA 

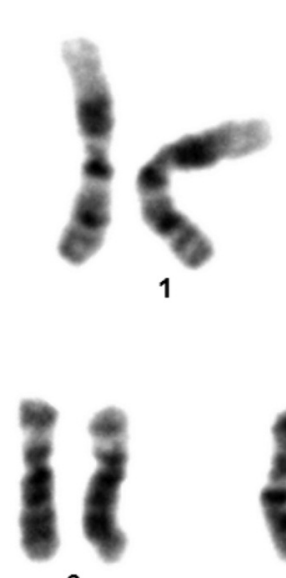

6

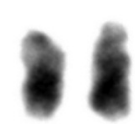

13

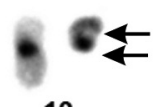

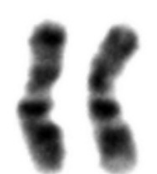

7

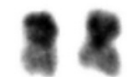

20

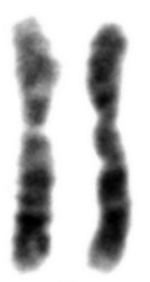

2

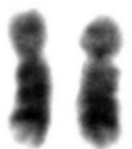

8

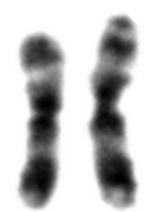

3

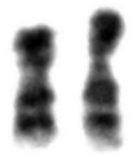

9

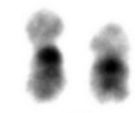

16

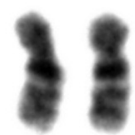

10

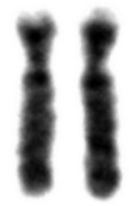

4

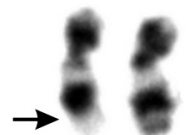

11

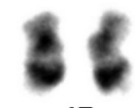

17

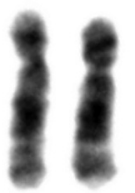

5

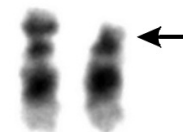

12

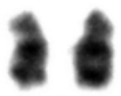

18

Figure 1. Cytogenetic analyses of the pediatric T-ALL. Karyogram showing the der(11)t(11;19)(q23;p13), del(12)(p11), der(15)?t(15;19)(q26;q11), and der(19)del(19)(q11)t(11;19)(q23;p13). Breakpoint positions are indicated by arrows.

polymerase II elongation complex $(37,38)$. The ELL protein modulates gene expression (39), plays an important role in embryogenesis (40), and is a partner of steroid receptors, TP53, hypoxia-inducible factor $1 \alpha$, and elongation-associated factors 1 and 2. (41-45). However, the exact mechanism of ELL activity in normal and neoplastic cells is still unclear.

The ELL protein has various functional domains. At the Nterminal, between amino acid residues 5 to 293 , it has the RNA polymerase II elongation factor ELL domain (pfam10390). This is bound stably to elongation-associated factors 1 and 2, and together these act as a strong regulator of transcription activity $(37,38,43,44,46)$. This $\mathrm{N}$-terminal domain is encoded by exons 1-6 of ELL (NM_006532.3). In addition to its elongation activation domain, ELL contains a RNA polymerase II interaction domain (37). This domain of ELL negatively regulates polymerase activity in promoter-specific transcription, is within the first 60 amino acids and is encoded by exons 1 and 2 of ELL $(37,47)$. A nuclear localization signal is found between amino acid residues 445-459 (encoded by exon 8). At the C-terminal part of the protein, there is an occludin homology domain (pfam07303). Occludin is an integral membrane protein that localizes to tight junctions (48). This domain represents a conserved region approximately 100 residues long between amino acid residues 513-614 thought to mediate protein interactions $(48,49)$. This C-terminal domain is encoded by exons 9-12 of ELL (NM_006532.3). Between amino acid residues 534-619 (encoded by exons 9-12) one also finds a SMC_prok_A domain (chromosome segregation protein SMC, primarily archaeal type TIGR02169). SMC (structural maintenance of chromosomes) proteins bind DNA and act to organize and segregate chromosomes for partition (50).

Three types of KMT2A-ELL fusion transcripts have been reported (51). In type 1 fusion transcripts, found in the majority of cases, exons 9, 10, 11 or 12 of KMT2A (within the major breakpoint cluster region) fuse to exon 2 of $E L L(11,30,52-$ 57). In type 2, KMT2A exon 9 [exon 10 according to Nilson et al. (27)] fuses to $E L L$ exon $3(58,59)$. Thus, types 1 and 2 of KMT2A-ELL proteins both maintain the ability to interact with RNA polymerase II and be active in transcription elongation, whereas the functional domain required for inhibition of promoter-specific initiation by ELL is absent (60). In type 3, exon 8 or 9 of $K M T 2 A$ fuses to exon 6 of $\operatorname{ELL~}(51,61-63)$. 


\section{$\mathbf{A}$}

$\operatorname{chr11}(\mathbf{q} 23.3)$\begin{tabular}{|l|l|l|l|}
\hline p15.4 & 15.1 & p1311p1211.2 \\
\hline
\end{tabular}

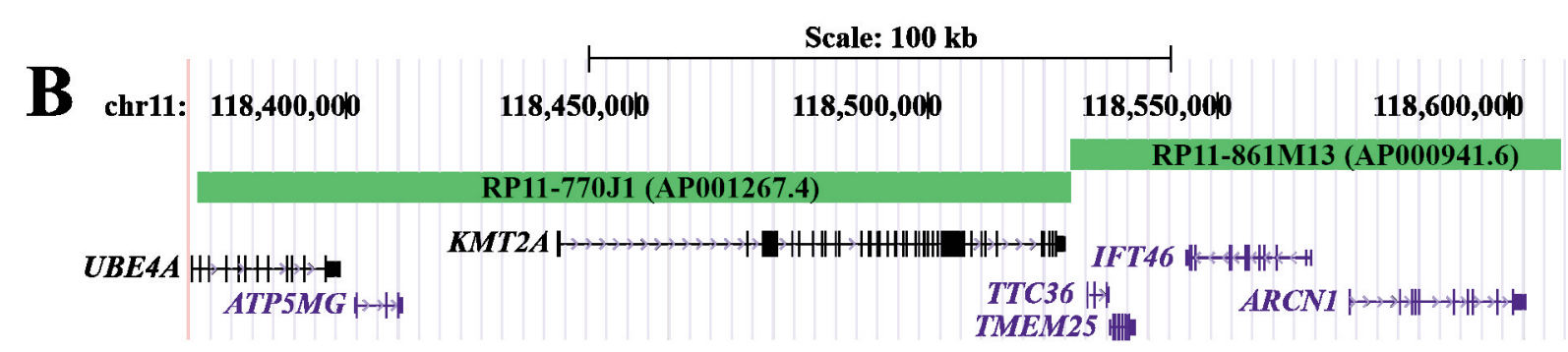

C

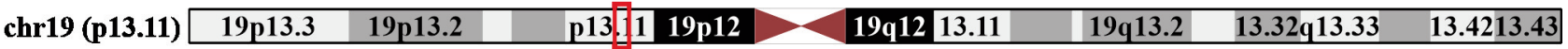
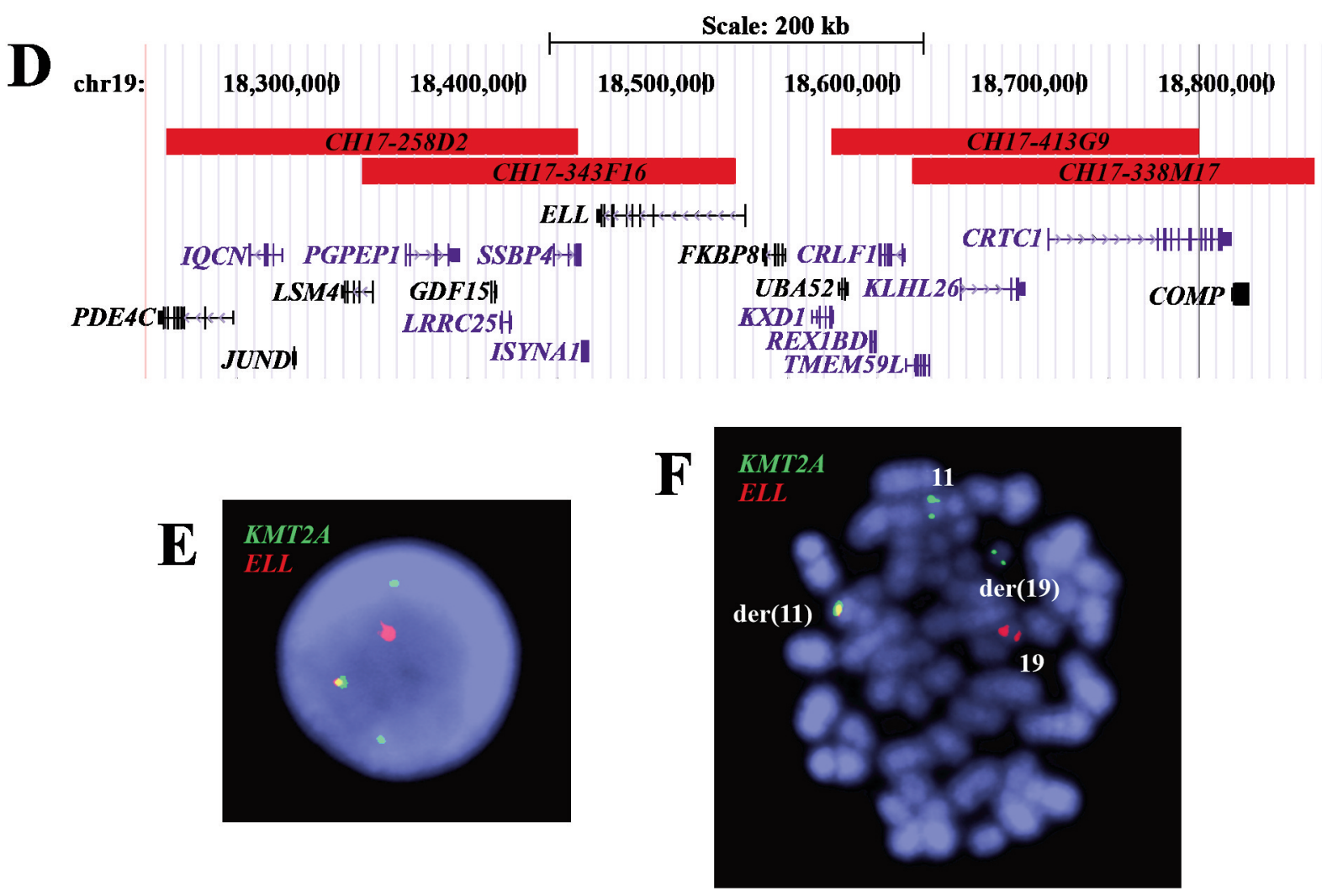

Figure 2. Fluorescence in situ hybridization (FISH) analysis of the pediatric T-ALL using a home-made, dual color fusion probe for the detection of the chimeric gene histone-lysine N-methyltransferase $2 A$ - elongation factor for RNA polymerase II (KMT2A-ELL) gene. (A) Ideogram of the chromosome 11 showing the mapping position of the KMT2A gene at 11q23.3 (vertical green line). (B) Diagram showing the FISH probes RP11$770 J 1$ and RP11-861M13 for KMT2A. The neighboring genes are also shown. (C) Ideogram of chromosome 19 showing the mapping position of the ELL gene at 19p13.11 (red box). (D) Diagram showing the FISH probes CH17-258D2, CH17-343F16, CH17-413G9, and CH17-338M17 for ELL. The neighboring genes in this region are also shown. (E) FISH results with the KMT2A (green signal) and ELL (red signal) probes on interphase nuclei. A nucleus with a yellow signal for the KMT2A-ELL fusion, a red signal for normal ELL, a green signal for normal KMT2A, and a green signal corresponding to the 3'end of the KMT2A which was moved to der(19). (F) FISH results with the KMT2A (green signal) and ELL (red signal) probes on a metaphase spread. A KMT2A-ELL fusion yellow signal on der(11), a normal KMT2A green signal on chromosome 11, a KMT2A green signal on der(19), and a normal ELL red signal on chromosome 19 are shown. 


\section{A $\quad K M T 2 A$ exon $20 \quad \downarrow \quad E L L$ exon 2}

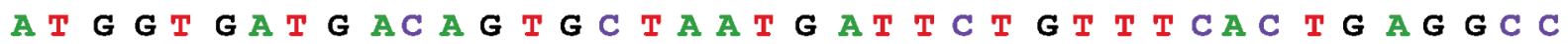

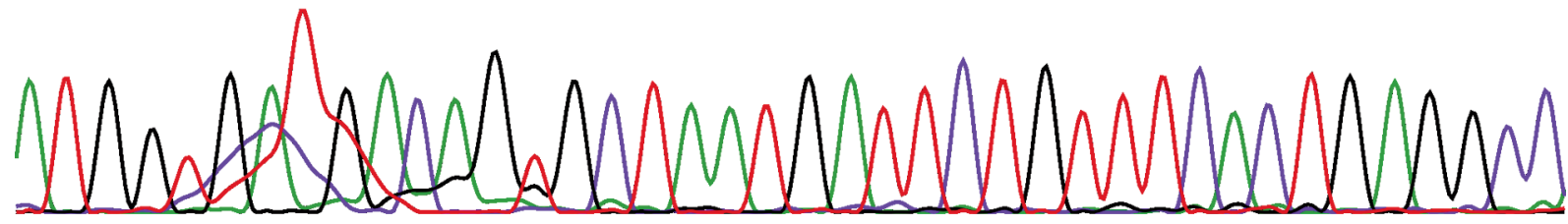

B ZNF56 exon $1 \downarrow K M T 2 A$ exon 21

TC C T G A T T C CA A A T T G G G T G C T G G T G T T T A T

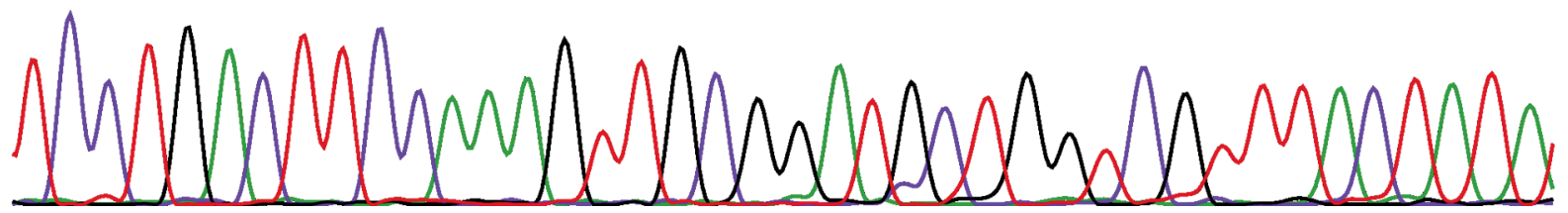

Figure 3. Molecular genetic analyses of the pediatric T-ALL. I(A) Partial sequence chromatogram showing the junction position of exon 20 of KMT2A with exon 2 of ELL in the chimeric transcript. (B) Partial sequence chromatogram showing the junction position of exon 1 of ZNF56 with exon 21 of KTM2A.

This transcript codes for a KMT2A-ELL protein which abolishes the function of the RNA polymerase II elongation factor ELL domain, i.e., it cannot interact with RNA polymerase II to active transcription elongation, nor can it mediate negative regulation of promoter-specific transcription initiation $(47,60)$. The KMT2A-ELL proteins which are encoded by the above-mentioned three fusion transcripts retain from the KMT2A protein the amino-terminal region which interacts with menin, the AT hooks which bind to the minor grove of DNA, the nuclear localization signal, and the CXXC domain which binds to unmethylated CpGs $(64,65)$. From the ELL protein they retain the nuclear localization signal, the three phosphorylation sites, the occludin homology domain, and the SMC_prok_A domain.

Our patient had a KMT2A-ELL chimeric transcript in which exon 20 of $K M T 2 A$ fused with exon 2 of $E L L$ (we have called it type 4 KMT2A-ELL chimeric transcript). Thus, the breakpoint is within the minor breakpoint cluster region of $K M T 2 A(8,30)$. To the best of our knowledge, this chimera was previously reported only in a 20 -year-old male patient who also had T-ALL, but with a seemingly normal karyotype (13). Based on the reference sequences of KMT2A (NM_005933.3/ NP_005924.2) and ELL (NM_006532.3/NP_006523.1), the chimeric KMT2A-ELL transcript codes for a 2461-amino acid residue protein and retains, in addition to the above-mentioned domains of KMT2A, the three PHD domains and the bromodomain together with ELL functional domains encoded by KMT2A-ELL transcripts 1-3. The presence of KMT2A PHD3 and bromodomain might be of importance in the role of the transcript 4 in leukemogenesis. PHD3 domain together with bromodomain are involved in a highly complex epigenetic mechanism (66).

Although more studies are required to address possible differences in the leukemogenesis of the different types of $K M T 2 A-E L L$ fusion transcripts, previous reports showed that the C-terminal region of ELL (occludin homology domain and SMC_prok_A domain) was necessary and sufficient for immortalization of myeloid progenitors by KMT2A-ELL, whereas the transcriptional elongation domain of ELL was nonessential $(60,67)$.

In addition to the $K M T 2 A-E L L$ fusion gene/transcript, our patient carried a novel reciprocal ZNF56-KMT2A fusion gene which, based on FISH results, was generated on the chromosome der(19)del(19)(q11)t(11;19)(q23;p13). ZNF56 maps on 19p13.11, codes for a zinc finger protein and RNA sequencing of total RNA from 20 human tissues showed it is expressed on all of them (https:/www.ncbi.nlm.nih.gov/ gene/7608). The ZNF56 gene maps on chromosome position chr19:19,887,383-19,946,990, whereas the ELL gene on position chr19:18,553,473-18,632,937. Therefore, in our case, it is likely that the area between these two genes has been deleted on der(19) in order to fuse 5' of ZNF56 and 3'of 
Panagopoulos et al: KMT2A-ELL and ZNF56-KMT2A Chimeras in Pediatric T-ALL

Table III. The published T-lineage acute lymphoblastic leukemias carrying a KMT2A-ELL fusion.

\begin{tabular}{lccc}
\hline Gender/Age & Reported karyotype & KMT2A-ELL fusion transcript & Reference (patient) \\
\hline Male/20 & $46, \mathrm{XY}$ & KMT2A exon 20-ELL exon 2 & (13) (patient A51) \\
Male/11 & $46, \mathrm{XY}$, ins $(19 ; 11)(\mathrm{p} 13.3 ; \mathrm{q} 23 \mathrm{q} 23), \operatorname{del}(12)(\mathrm{p} 13)$ & KMT2A exon $10-E L L$ exon 2 & $(14)$ (patient USI: PAUAJA) \\
Male/11 & $46, \mathrm{XY}$ & Not determined & $(15)$ (patient 18$)$ \\
Male/17 & $46, \mathrm{XY}, \mathrm{t}(11 ; 19)(\mathrm{q} 23 ; \mathrm{p} 13.1), \mathrm{t}(12 ; 14)(\mathrm{p} 11.2 ; \mathrm{q} 24)$ & Not determined & $(15)(\mathrm{patient} 19)$ \\
Male/13 & $46, \mathrm{XY}, \operatorname{der}(11) \mathrm{t}(11 ; 19)(\mathrm{q} 23 ; \mathrm{p} 13), \operatorname{del}(12)(\mathrm{p} 11), \operatorname{der}(15) ?$ & KMT2A exon 20-ELL exon 2 & Present study \\
& $\mathrm{t}(15 ; 19)(\mathrm{q} 26 ; \mathrm{q} 11), \operatorname{der}(19) \operatorname{del}(19)(\mathrm{q} 11) \mathrm{t}(11 ; 19)(\mathrm{q} 23 ; \mathrm{p} 13)$ & & \\
\hline
\end{tabular}

$K M T 2 A$. This interpretation is supported by the fact that the FISH-analysis only showed signal for KMT2A (green), but no red signal for $E L L$, on $\operatorname{der}(19)$ (Figure 2E and F).

In the detected ZNF56-KMT2A fusion transcript the untranslated exon 1 of the ZNF56 gene (from 19p13.11) fused to exon 21 of $K M T 2 A$. In exon 21 of $K M T 2 A$ there is an ATG which could act as a starting codon (NM_005933.3; position 5790-5793). Thus, in ZNF56-KMT2A the part of KMT2A coding for the last 2047 amino acids (positions 1923-3969 in the sequence with accession number NP_005924.2) is under control of the ZNF56 promoter. This part of the KMT2A protein contains PHD4, phenylalanine-tyrosine-rich N-terminal domain (FYRN), threonine aspartase 1 (TASP1) cleavage site 1, TASP1 cleavage site 2, transactivation domain, phenylalanine-tyrosinerich C-terminal domain (FYRC), WD repeat-containing protein 5 (WDR5) interaction motif, Su(Var)3-9, enhancer-of-zeste, trithorax domain (SET), and post-SET domain (68).

Fusion genes in which the $K M T 2 A$ is the 3 '-end partner gene (reciprocal-KMT2A) were shown to have oncogenetic properties (69). In a mouse model, expression of $A F F 1$ KMT2A (also known as AF4-MLL), the reciprocal-KMT2A product of the $\mathrm{t}(4 ; 11)(\mathrm{q} 21 ; \mathrm{q} 23)$, was found to induce ALL (70). In another study, expression of $A F F 1-K M T 2 A$ in cord blood CD34-positive cells transiently enhanced long-term hematopoietic reconstitution in immunodeficient mice, but it was not sufficient for leukemia development (71). AFF 1$K M T 2 A$ was also shown to alter transcription and epigenetic signatures, to mediate transcriptional elongation of 5lipoxygenase mRNA, and to interact with the SIAH ubiquitin ligases (72-74). Oncogenic properties were also found for the reciprocal $K M T 2 A$ fusions $N E B L-K M T 2 A, L A S P 1-K M T 2 A$, $M A M L 2-K M T 2 A$, and SMAP1-KMT2A generated by the chromosome aberrations $\mathrm{t}(10 ; 11)(\mathrm{p} 12 ; \mathrm{q} 23), \mathrm{t}(11 ; 17)(\mathrm{q} 23 ; \mathrm{q} 12)$ $\operatorname{inv}(11)(\mathrm{q} 21 \mathrm{q} 23)$, and $\mathrm{t}(6 ; 11)(\mathrm{q} 13 ; \mathrm{q} 23)$, respectively $(69,75$, 76). Recently, YAP1-KMT2A and VIM-KMT2A fusion genes were found in sarcomas (77-80) and an $M N 1-K M T 2 A$ fusion in a case of dural-based spindle cell neoplasm (81).

The Mitelman Database of Chromosome Aberrations and Gene Fusions in Cancer (82) contains information on 428 cases of various hematological malignancies with the chromosome translocation $\mathrm{t}(11 ; 19)(\mathrm{q} 23 ; \mathrm{p} 13)$ (database last updated on October 15, 2020). Only 44 of them $(10.3 \%)$ are T-lineage ALL/lymphoblastic lymphoma. However, the KMT2A-ELL fusion (detected by FISH, RT-PCR, or high throughput sequencing) was found in five male patients with T-ALL, the present case included (Table III) (13-15). The fusion transcript junction was between exon 10 of KMT2A and exon 2 of $E L L$ in one case (14), between exon 20 of $K M T 2 A$ and exon 2 of ELL in two cases [(13), present case], whereas two cases were reported without information on the junction of the fusion transcript (15). The current data are very limited in order to draw any conclusion on the prognosis of KMT2A-ELL fusion in T-ALL but in an international study with pediatric AML patients, the 5-year overall survival and the 5-year event-free survival of patients with $\mathrm{t}(11 ; 19)(\mathrm{q} 23 ; \mathrm{p} 13.1)$ (corresponding to KMT2A-ELL) were $61 \%$ and $46 \%$, respectively (83).

In conclusion, we describe herein a pediatric T-ALL with a KMT2A-ELL and a novel ZNF56-KMT2A fusion genes generated on the derivative chromosomes 11 and 19 , respectively. A very rare $K M T 2 A-E L L$ fusion transcript was found in which exon 20 of KMT2A fused to exon 2 of $E L L$. This fusion transcript was previously reported only in a 20 year-old male patient who also had T-ALL. In the novel ZNF56-KMT2A fusion transcript the untranslated exon 1 of the ZNF56 gene fused to exon 21 of KMT2A.

\section{Conflicts of Interest}

The Authors declare that they have no potential conflicts of interest in regard to this study.

\section{Authors' Contributions}

IP designed and supervised the experiments, performed bioinformatics analysis, molecular genetic experiments, evaluated the data, and drafted the manuscript. KA performed cytogenetic, FISH, and molecular experiments, and evaluated the data. ME-O evaluated the cytogenetic and FISH data. AGR made clinical evaluations and treated the patient. MCM-K made clinical evaluations and treated the patient. FM evaluated the cytogenetic and FISH data. SH evaluated the data and assisted with writing of the manuscript. All Authors read and approved the final manuscript. 


\section{Acknowledgements}

This work was supported by Grants from Radiumhospitalets Legater.

\section{References}

1 Heim S and Mitelman F: Cancer cytogenetics: Chromosomal and molecular genetic abberations of tumor cells. Fourth Edition edn. Wiley-Blackwell, 2015.

2 Biggerstaff JS, Liu W, Slovak ML, Bobadilla D, Bryant E, Glotzbach C and Shaffer LG: A dual-color FISH assay distinguishes between ELL and MLLT1 (ENL) gene rearrangements in t $(11 ; 19)$ positive acute leukemia. Leukemia 20(11): 2046-2050, 2006. PMID: 16990786. DOI: 10.1038/sj.leu.2404371

3 Huret JL, Brizard A, Slater R, Charrin C, Bertheas MF, Guilhot F, Hählen K, Kroes W, van Leeuwen E, Schoot EV, Beishuizen A, Tanzer $\mathrm{J}$ and Hagemeijer A: Cytogenetic heterogeneity in $t(11 ; 19)$ acute leukemia: clinical, hematological and cytogenetic analyses of 48 patients - updated published cases and 16 new observations. Leukemia 7(2): 152-160, 1993. PMID: 8426468.

4 Tkachuk DC, Kohler S and Cleary ML: Involvement of a homolog of Drosophila trithorax by 11q23 chromosomal translocations in acute leukemias. Cell 71(4): 691-700, 1992. PMID: 1423624. DOI: 10.1016/0092-8674(92)90602-9

5 Corral J, Forster A, Thompson S, Lampert F, Kaneko Y, Slater R, Kroes WG, van der Schoot CE, Ludwig WD, Karpas A, Pocock C, Cotter F and Rabbitts TH: Acute leukemias of different lineages have similar MLL gene fusions encoding related chimeric proteins resulting from chromosomal translocation. Proc Natl Acad Sci USA 90(18): 8538-8542, 1993. PMID: 8378328. DOI: 10.1073/pnas.90.18.8538

6 Yamamoto K, Seto M, Komatsu H, Iida S, Akao Y, Kojima S, Kodera Y, Nakazawa S, Ariyoshi Y, Takahashi T and Ueda R: Two distinct portions of LTG19/ENL at 19p13 are involved in t(11;19) leukemia. Oncogene 8(10): 2617-2625, 1993. PMID: 8378076.

7 So CW, Caldas C, Liu MM, Chen SJ, Huang QH, Gu LJ, Sham MH, Wiedemann LM and Chan LC: EEN encodes for a member of a new family of proteins containing an Src homology 3 domain and is the third gene located on chromosome 19p13 that fuses to MLL in human leukemia. Proc Natl Acad Sci USA 94(6): 25632568, 1997. PMID: 9122235. DOI: 10.1073/pnas.94.6.2563

8 Meyer C, Burmeister T, Groger D, Tsaur G, Fechina L, Renneville A, Sutton R, Venn NC, Emerenciano M, Pombo-de-Oliveira MS, Barbieri Blunck C, Almeida Lopes B, Zuna J, Trka J, Ballerini P, Lapillonne H, De Braekeleer M, Cazzaniga G, Corral Abascal L, van der Velden VHJ, Delabesse E, Park TS, Oh SH, Silva MLM, Lund-Aho T, Juvonen V, Moore AS, Heidenreich O, Vormoor J, Zerkalenkova E, Olshanskaya Y, Bueno C, Menendez P, TeiglerSchlegel A, Zur Stadt U, Lentes J, Gohring G, Kustanovich A, Aleinikova O, Schafer BW, Kubetzko S, Madsen HO, Gruhn B, Duarte X, Gameiro P, Lippert E, Bidet A, Cayuela JM, Clappier E, Alonso CN, Zwaan CM, van den Heuvel-Eibrink MM, Izraeli S, Trakhtenbrot L, Archer P, Hancock J, Moricke A, Alten J, Schrappe M, Stanulla M, Strehl S, Attarbaschi A, Dworzak M, Haas OA, Panzer-Grumayer R, Sedek L, Szczepanski T, Caye A, Suarez L, Cave H and Marschalek R: The MLL recombinome of acute leukemias in 2017. Leukemia 32(2): 273-284, 2018. PMID: 28701730. DOI: 10.1038/leu.2017.213
9 Duhoux FP, Ameye G, Libouton JM, Bahloula K, Iossifidis S, Chantrain CF, Demoulin JB and Poirel HA: The $\mathrm{t}(11 ; 19)(\mathrm{q} 23 ; \mathrm{p} 13)$ fusing MLL with MYO1F is recurrent in infant acute myeloid leukemias. Leuk Res 35(9): e171-172, 2011. PMID: 21620472. DOI: 10.1016/j.leukres.2011.04.022

10 Taki T, Akiyama M, Saito S, Ono R, Taniwaki M, Kato Y, Yuza $\mathrm{Y}$, Eto $\mathrm{Y}$ and Hayashi Y: The MYO1F, unconventional myosin type $1 \mathrm{~F}$, gene is fused to MLL in infant acute monocytic leukemia with a complex translocation involving chromosomes 7, 11, 19 and 22. Oncogene 24(33): 5191-5197, 2005. PMID: 15897884. DOI: 10.1038/sj.onc.1208711

11 Thirman MJ, Levitan DA, Kobayashi H, Simon MC and Rowley JD: Cloning of ELL, a gene that fuses to MLL in a $\mathrm{t}(11 ; 19)(\mathrm{q} 23 ; \mathrm{p} 13.1)$ in acute myeloid leukemia. Proc Natl Acad Sci USA 91(25): 12110-12114, 1994. PMID: 7991593. DOI: 10.1073/pnas.91.25.12110

12 Turkmen S, Timmermann B, Bartels G, Groger D, Meyer C, Schwartz S, Haferlach C, Rieder H, Gokbuget N, Hoelzer D, Marschalek R and Burmeister T: Involvement of the MLL gene in adult T-lymphoblastic leukemia. Genes Chromosomes Cancer 51(12): 1114-1124, 2012. PMID: 22927255. DOI: 10.1002/ gcc. 21996

13 Chen B, Jiang L, Zhong ML, Li JF, Li BS, Peng LJ, Dai YT, Cui BW, Yan TQ, Zhang WN, Weng XQ, Xie YY, Lu J, Ren RB, Chen SN, Hu JD, Wu DP, Chen Z, Tang JY, Huang JY, Mi JQ and Chen SJ: Identification of fusion genes and characterization of transcriptome features in T-cell acute lymphoblastic leukemia. Proc Natl Acad Sci USA 115(2): 373-378, 2018. PMID: 29279377. DOI: $10.1073 /$ pnas.1717125115

14 Liu Y, Easton J, Shao Y, Maciaszek J, Wang Z, Wilkinson MR, McCastlain K, Edmonson M, Pounds SB, Shi L, Zhou X, Ma X, Sioson E, Li Y, Rusch M, Gupta P, Pei D, Cheng C, Smith MA, Auvil JG, Gerhard DS, Relling MV, Winick NJ, Carroll AJ, Heerema NA, Raetz E, Devidas M, Willman CL, Harvey RC, Carroll WL, Dunsmore KP, Winter SS, Wood BL, Sorrentino BP, Downing JR, Loh ML, Hunger SP, Zhang $\mathrm{J}$ and Mullighan CG: The genomic landscape of pediatric and young adult T-lineage acute lymphoblastic leukemia. Nat Genet 49(8): 1211-1218, 2017. PMID: 28671688. DOI: 10.1038/ng.3909

15 Peterson JF, Baughn LB, Pearce KE, Williamson CM, Benevides Demasi JC, Olson RM, Goble TA, Meyer RG, Greipp PT and Ketterling RP: KMT2A (MLL) rearrangements observed in pediatric/young adult T-lymphoblastic leukemia/lymphoma: A 10 -year review from a single cytogenetic laboratory. Genes Chromosomes Cancer 57(11): 541-546, 2018. PMID: 30203571. DOI: $10.1002 / \mathrm{gcc} .22666$

16 Toft N, Birgens H, Abrahamsson J, Griskevicius L, Hallbook H, Heyman M, Klausen TW, Jonsson OG, Palk K, Pruunsild K, Quist-Paulsen P, Vaitkeviciene G, Vettenranta K, Asberg A, Frandsen TL, Marquart HV, Madsen HO, Noren-Nystrom U and Schmiegelow K: Results of NOPHO ALL2008 treatment for patients aged 1-45 years with acute lymphoblastic leukemia. Leukemia 32(3): 606-615, 2018. PMID: 28819280. DOI: 10.1038/leu.2017.265

17 Czepulkowski B: Basic techniques for the preparation and analysis of chromosomes from bone marrow and leukaemic blood. In: Human cytogenetics: malignancy and acquired abnormalities. Rooney DE (ed.). Oxford University Press: New York, pp. 1-26, 2001. 
18 Panagopoulos I, Bjerkehagen B, Gorunova L, Taksdal I and Heim S: Rearrangement of chromosome bands 12q14 15 causing HMGA2-SOX5 gene fusion and HMGA2 expression in extraskeletal osteochondroma. Oncol Rep 34(2): 577-584, 2015. PMID: 26043835. DOI: 10.3892/or.2015.4035

19 Panagopoulos I, Gorunova L, Andersen K, Lund-Iversen M, Lobmaier I, Micci F and Heim S: NDRG1-PLAG1 and TRPS1PLAG1 fusion genes in chondroid syringoma. Cancer Genomics Proteomics 17(3): 237-248, 2020. PMID: 32345665. DOI: $10.21873 /$ cgp. 20184

20 Schroeder A, Mueller O, Stocker S, Salowsky R, Leiber M, Gassmann M, Lightfoot S, Menzel W, Granzow M and Ragg T: The RIN: an RNA integrity number for assigning integrity values to RNA measurements. BMC Mol Biol 7: 3, 2006. PMID: 16448564. DOI: 10.1186/1471-2199-7-3

21 Kangaspeska S, Hultsch S, Edgren H, Nicorici D, Murumagi A and Kallioniemi O: Reanalysis of RNA-sequencing data reveals several additional fusion genes with multiple isoforms. PLoS One 7(10): e48745, 2012. PMID: 23119097. DOI: 10.1371 /journal.pone .0048745

22 Nicorici D, Satalan H, Edgren H, Kangaspeska S, Murumagi A, Kallioniemi O, Virtanen S and Kikku O: FusionCatcher - a tool for finding somatic fusion genes in paired-end RNA-sequencing data. bioRxiv, 2014. DOI: 10.1101/011650

23 Altschul SF, Gish W, Miller W, Myers EW and Lipman DJ: Basic local alignment search tool. J Mol Biol 215(3): 403-410, 1990. PMID: 2231712. DOI: 10.1016/S0022-2836(05)80360-2

24 Kent WJ: BLAT - the BLAST-like alignment tool. Genome Res 12(4): 656-664, 2002. PMID: 11932250. DOI: 10.1101/gr.229202

25 Kent WJ, Sugnet CW, Furey TS, Roskin KM, Pringle TH, Zahler $\mathrm{AM}$ and Haussler D: The human genome browser at UCSC. Genome Res 12(6): 996-1006, 2002. PMID: 12045153. DOI: $10.1101 /$ gr.229102

26 Meyer C, Hofmann J, Burmeister T, Groger D, Park TS, Emerenciano M, Pombo de Oliveira M, Renneville A, Villarese P, Macintyre E, Cave H, Clappier E, Mass-Malo K, Zuna J, Trka J, De Braekeleer E, De Braekeleer M, Oh SH, Tsaur G, Fechina L, van der Velden VH, van Dongen JJ, Delabesse E, Binato R, Silva ML, Kustanovich A, Aleinikova O, Harris MH, Lund-Aho T, Juvonen V, Heidenreich O, Vormoor J, Choi WW, Jarosova M, Kolenova A, Bueno C, Menendez P, Wehner S, Eckert C, Talmant P, Tondeur S, Lippert E, Launay E, Henry C, Ballerini $\mathrm{P}$, Lapillone H, Callanan MB, Cayuela JM, Herbaux C, Cazzaniga G, Kakadiya PM, Bohlander S, Ahlmann M, Choi JR, Gameiro P, Lee DS, Krauter J, Cornillet-Lefebvre P, Te Kronnie G, Schafer BW, Kubetzko S, Alonso CN, zur Stadt U, Sutton R, Venn NC, Izraeli S, Trakhtenbrot L, Madsen HO, Archer P, Hancock J, Cerveira N, Teixeira MR, Lo Nigro L, Moricke A, Stanulla M, Schrappe M, Sedek L, Szczepanski T, Zwaan CM, Coenen EA, van den Heuvel-Eibrink MM, Strehl S, Dworzak M, Panzer-Grumayer R, Dingermann $\mathrm{T}$, Klingebiel $\mathrm{T}$ and Marschalek R: The MLL recombinome of acute leukemias in 2013. Leukemia 27(11): 2165-2176, 2013. PMID: 23628958. DOI: $10.1038 /$ leu.2013.135

27 Nilson I, Lochner K, Siegler G, Greil J, Beck JD, Fey GH and Marschalek R: Exon/intron structure of the human ALL-1 (MLL) gene involved in translocations to chromosomal region 11q23 and acute leukaemias. Br J Haematol 93(4): 966-972, 1996. PMID: 8703835. DOI: 10.1046/j.1365-2141.1996.d011748.x
28 Emerenciano M, Meyer C, Mansur MB, Marschalek R, Pombode-Oliveira MS and Brazilian Collaborative Study Group of Infant Acute Leukaemia: The distribution of MLL breakpoints correlates with outcome in infant acute leukaemia. $\mathrm{Br} \mathrm{J}$ Haematol 161(2): 224-236, 2013. PMID: 23432364. DOI: $10.1111 / \mathrm{bjh} .12250$

29 Rössler T and Marschalek R: An alternative splice process renders the MLL protein either into a transcriptional activator or repressor. Pharmazie 68(7): 601-607, 2013. PMID: 23923644. DOI: $10.1055 / \mathrm{s}-0033-1343653$

30 Meyer C, Lopes BA, Caye-Eude A, Cave H, Arfeuille C, Cuccuini W, Sutton R, Venn NC, Oh SH, Tsaur G, Escherich G, Feuchtinger T, Kosasih HJ, Khaw SL, Ekert PG, Pombo-de-Oliveira MS, Bidet A, Djahanschiri B, Ebersberger I, Zaliova M, Zuna J, Zermanova Z, Juvonen V, Grumayer RP, Fazio G, Cazzaniga G, Larghero P, Emerenciano M and Marschalek R: Human MLL/KMT2A gene exhibits a second breakpoint cluster region for recurrent MLLUSP2 fusions. Leukemia 33(9): 2306-2340, 2019. PMID: 30899083. DOI: 10.1038/s41375-019-0451-7

31 Ali M, Hom RA, Blakeslee W, Ikenouye L and Kutateladze TG: Diverse functions of PHD fingers of the MLL/KMT2 subfamily. Biochim Biophys Acta 1843(2): 366-371, 2014. PMID: 24291127. DOI: 10.1016/j.bbamcr.2013.11.016

32 Yokoyama A, Ficara F, Murphy MJ, Meisel C, Naresh A, Kitabayashi I and Cleary ML: Proteolytically cleaved MLL subunits are susceptible to distinct degradation pathways. J Cell Sci 124(Pt 13): 2208-2219, 2011. PMID: 21670200. DOI: $10.1242 /$ jcs. 080523

33 Wang J, Muntean AG, Wu L and Hess JL: A subset of mixed lineage leukemia proteins has plant homeodomain (PHD)mediated E3 ligase activity. J Biol Chem 287(52): 43410-43416, 2012. PMID: 23129768. DOI: 10.1074/jbc.M112.423855

34 Fair K, Anderson M, Bulanova E, Mi H, Tropschug M and Diaz MO: Protein interactions of the MLL PHD fingers modulate MLL target gene regulation in human cells. Mol Cell Biol 21(10): 3589-3597, 2001. PMID: 11313484. DOI: 10.1128/MCB.21.10.3589-3597.2001

35 Muntean AG, Giannola D, Udager AM and Hess JL: The PHD fingers of MLL block MLL fusion protein-mediated transformation. Blood 112(12): 4690-4693, 2008. PMID: 18796627. DOI: 10.1182/blood-2008-01-134056

36 Chen J, Santillan DA, Koonce M, Wei W, Luo R, Thirman MJ, Zeleznik-Le NJ and Diaz MO: Loss of MLL PHD finger 3 is necessary for MLL-ENL-induced hematopoietic stem cell immortalization. Cancer Res 68(15): 6199-6207, 2008. PMID: 18676843. DOI: 10.1158/0008-5472.CAN-07-6514

37 Shilatifard A, Haque D, Conaway RC and Conaway JW: Structure and function of RNA polymerase II elongation factor ELL. Identification of two overlapping ELL functional domains that govern its interaction with polymerase and the ternary elongation complex. J Biol Chem 272(35): 22355-22363, 1997. PMID: 9268387. DOI: 10.1074/jbc.272.35.22355

38 Shilatifard A, Lane WS, Jackson KW, Conaway RC and Conaway JW: An RNA polymerase II elongation factor encoded by the human ELL gene. Science 271(5257): 1873-1876, 1996. PMID: 8596958. DOI: 10.1126/science.271.5257.1873

39 Smith E, Lin C and Shilatifard A: The super elongation complex (SEC) and MLL in development and disease. Genes Dev 25(7): 661-672, 2011. PMID: 21460034. DOI: 10.1101/ $\operatorname{gad} .2015411$ 
40 Mitani K, Yamagata T, Iida C, Oda H, Maki K, Ichikawa M, Asai T, Honda H, Kurokawa M and Hirai H: Nonredundant roles of the elongation factor MEN in postimplantation development. Biochem Biophys Res Commun 279(2): 563-567, 2000. PMID: 11118326. DOI: $10.1006 /$ bbrc. 2000.3970

41 Liu L, Ai J, Xiao W, Liu J, Wang Y, Xin D, He Z, Guo Y and Wang Z: ELL is an HIF-1alpha partner that regulates and responds to hypoxia response in PC3 cells. Prostate 70(7): 797805, 2010. PMID: 20166137. DOI: 10.1002/pros.21113

42 Pascual-Le Tallec L, Simone F, Viengchareun S, Meduri G, Thirman MJ and Lombes M: The elongation factor ELL (elevennineteen lysine-rich leukemia) is a selective coregulator for steroid receptor functions. Mol Endocrinol 19(5): 1158-1169, 2005. PMID: 15650021. DOI: 10.1210/me.2004-0331

43 Simone F, Luo RT, Polak PE, Kaberlein JJ and Thirman MJ: ELL-associated factor 2 (EAF2), a functional homolog of EAF1 with alternative ELL binding properties. Blood 101(6): 23552362, 2003. PMID: 12446457. DOI: 10.1182/blood-2002-061664

44 Simone F, Polak PE, Kaberlein JJ, Luo RT, Levitan DA and Thirman MJ: EAF1, a novel ELL-associated factor that is delocalized by expression of the MLL-ELL fusion protein. Blood 98(1): 201-209, 2001. PMID: 11418481. DOI: 10.1182/blood.v98.1.201

45 Wiederschain D, Kawai H, Gu J, Shilatifard A and Yuan ZM: Molecular basis of p53 functional inactivation by the leukemic protein MLL-ELL. Mol Cell Biol 23(12): 4230-4246, 2003. PMID: 12773566. DOI: 10.1128/mcb.23.12.4230-4246.2003

46 Banks CA, Kong SE, Spahr H, Florens L, Martin-Brown S, Washburn MP, Conaway JW, Mushegian A and Conaway RC: Identification and characterization of a Schizosaccharomyces pombe RNA polymerase II elongation factor with similarity to the metazoan transcription factor ELL. J Biol Chem 282(8): 57615769, 2007. PMID: 17150956. DOI: 10.1074/jbc.M610393200

47 Shilatifard A: Identification and purification of the Holo-ELL complex. Evidence for the presence of ELL-associated proteins that suppress the transcriptional inhibitory activity of ELL. J Biol Chem 273(18): 11212-11217, 1998. PMID: 9556611. DOI: $10.1074 /$ jbc.273.18.11212

48 Furuse M, Hirase T, Itoh M, Nagafuchi A, Yonemura S, Tsukita $\mathrm{S}$ and Tsukita S: Occludin: a novel integral membrane protein localizing at tight junctions. J Cell Biol 123(6 Pt 2): 1777-1788, 1993. PMID: 8276896. DOI: 10.1083/jcb.123.6.1777

49 Feldman GJ, Mullin JM and Ryan MP: Occludin: structure, function and regulation. Adv Drug Deliv Rev 57(6): 883-917, 2005. PMID: 15820558. DOI: 10.1016/j.addr.2005.01.009

50 Cobbe $\mathrm{N}$ and Heck MM: The evolution of SMC proteins: phylogenetic analysis and structural implications. Mol Biol Evol 21(2): 332-347, 2004. PMID: 14660695. DOI: 10.1093/ molbev/msh023

51 Panagopoulos I, Gorunova L, Kerndrup G, Spetalen S, Tierens A, Osnes LT, Andersen K, Muller LS, Hellebostad M, Zeller B and Heim S: Rare MLL-ELL fusion transcripts in childhood acute myeloid leukemia-association with young age and myeloid sarcomas? Exp Hematol Oncol 5: 8, 2015. PMID: 26949571. DOI: $10.1186 / \mathrm{s} 40164-016-0037-2$

52 De Braekeleer E, Meyer C, Douet-Guilbert N, Basinko A, Le Bris MJ, Morel F, Berthou C, Marschalek R, Ferec C and De Braekeleer M: Identification of MLL partner genes in 27 patients with acute leukemia from a single cytogenetic laboratory. Mol
Oncol 5(6): 555-563, 2011. PMID: 21900057. DOI: 10.1016/ j.molonc.2011.08.003

53 Megonigal MD, Rappaport EF, Wilson RB, Jones DH, Whitlock JA, Ortega JA, Slater DJ, Nowell PC and Felix CA: Panhandle PCR for cDNA: a rapid method for isolation of MLL fusion transcripts involving unknown partner genes. Proc Natl Acad Sci USA 97(17): 9597-9602, 2000. PMID: 10920186. DOI: 10.1073/pnas.150241797

54 Mitani K, Kanda Y, Ogawa S, Tanaka T, Inazawa J, Yazaki Y and Hirai $\mathrm{H}$ : Cloning of several species of MLL/MEN chimeric cDNAs in myeloid leukemia with $\mathrm{t}(11 ; 19)(\mathrm{q} 23 ; \mathrm{p} 13.1)$ translocation. Blood 85(8): 2017-2024, 1995. PMID: 7718874.

55 Rubnitz JE, Behm FG, Curcio-Brint AM, Pinheiro RP, Carroll AJ, Raimondi SC, Shurtleff SA and Downing JR: Molecular analysis of $\mathrm{t}(11 ; 19)$ breakpoints in childhood acute leukemias. Blood 87(11): 4804-4808, 1996. PMID: 8639852.

56 Takeuchi M, Nakaseko C, Miyagi S, Takeda Y, Ozawa S, Ohwada C, Cho R, Nishimura M, Saito Y and Iwama A: Clonal expansion of non-leukemic cells expressing two novel MLLELL variants differing in transforming activity. Leukemia 22(4): 861-864, 2008. PMID: 17882281. DOI: 10.1038/sj.leu.2404954

57 Yamamoto K, Nagata K, Tsurukubo Y, Inagaki K, Ono R, Taki T, Hayashi Y and Hamaguchi H: Translocation $(8 ; 12)(\mathrm{q} 13 ; \mathrm{p} 13)$ during disease progression in acute myelomonocytic leukemia with $\mathrm{t}(11 ; 19)(\mathrm{q} 23 ; \mathrm{p} 13.1)$. Cancer Genet Cytogenet 137(1): 64-67, 2002. PMID: 12377416. DOI: 10.1016/s0165-4608(02)00555-1

58 Kakihana K, Kubo F, Wakabayashi S, Kurosu T, Miki T, Murakami N and Miura O: A novel variant form of MLL-ELL fusion transcript with $\mathrm{t}(11 ; 19)(\mathrm{q} 23 ; \mathrm{p} 13.1)$ in chronic myelomonocytic leukemia transforming to acute myeloid leukemia. Cancer Genet Cytogenet 184(2): 109-112, 2008. PMID: 18617060. DOI: 10.1016/j.cancergencyto.2008.04.001

59 Tuborgh A, Meyer C, Marschalek R, Preiss B, Hasle H and Kjeldsen E: Complex three-way translocation involving MLL, ELL, RREB1, and CMAHP genes in an infant with acute myeloid leukemia and $\mathrm{t}(6 ; 19 ; 11)(\mathrm{p} 22.2 ; \mathrm{p} 13.1 ; \mathrm{q} 23.3)$. Cytogenet Genome Res 141(1): 7-15, 2013. PMID: 23735562. DOI: $10.1159 / 000351224$

60 DiMartino JF, Miller T, Ayton PM, Landewe T, Hess JL, Cleary ML and Shilatifard A: A carboxy-terminal domain of ELL is required and sufficient for immortalization of myeloid progenitors by MLL-ELL. Blood 96(12): 3887-3893, 2000. PMID: 11090074.

61 De Braekeleer E, Douet-Guilbert N, Meyer C, Morel F, Marschalek R and De Braekeleer M: MLL-ELL fusion gene in two infants with acute monoblastic leukemia and myeloid sarcoma. Leuk Lymphoma 53(6): 1222-1224, 2012. PMID: 22149207. DOI: $10.3109 / 10428194.2011 .648632$

62 De Braekeleer E, Meyer C, Douet-Guilbert N, Morel F, Le Bris MJ, Marschalek R, Ferec C and De Braekeleer M: A complex $1 ; 19 ; 11$ translocation involving the MLL gene in a patient with congenital acute monoblastic leukemia identified by molecular and cytogenetic techniques. Ann Hematol 88(8): 795-797, 2009. PMID: 19107484. DOI: 10.1007/s00277-008-0656-8

63 Uemura S, Tamura A, Saito A, Hasegawa D, Nino N, Yokoi T, Tahara T, Kozaki A, Kishimoto K, Ishida T, Kawasaki K, Mori $\mathrm{T}$, Nishimura N, Ishimae $\mathrm{M}$, Eguchi $\mathrm{M}$ and Kosaka $\mathrm{Y}$ : Reemergence of translocation $\mathrm{t}(11 ; 19)(\mathrm{q} 23 ; \mathrm{p} 13.1)$ in the absence of clinically overt leukemia. Int J Hematol 106(6): 847-851, 2017. PMID: 28669059. DOI: 10.1007/s12185-017-2289-y 
64 Krivtsov AV, Hoshii $\mathrm{T}$ and Armstrong SA: Mixed-Lineage Leukemia Fusions and Chromatin in Leukemia. Cold Spring Harb Perspect Med 7(11): a026658, 2017. PMID: 28242784. DOI: 10.1101/cshperspect.a026658

65 Muntean AG: Mechanisms of mixed-lineage leukemia. Int J Hematol Oncol 2(3): 207-217, 2013. PMID: 24563734. DOI: 10.2217/ijh.13.20

66 Wang Z, Song J, Milne TA, Wang GG, Li H, Allis CD and Patel DJ: Pro isomerization in MLL1 PHD3-bromo cassette connects $\mathrm{H} 3 \mathrm{~K} 4$ me readout to $\mathrm{CyP} 33$ and HDAC-mediated repression. Cell 141(7): 1183-1194, 2010. PMID: 20541251. DOI: 10.1016/j.cell.2010.05.016

67 Luo RT, Lavau C, Du C, Simone F, Polak PE, Kawamata S and Thirman MJ: The elongation domain of ELL is dispensable but its ELL-associated factor 1 interaction domain is essential for MLLELL-induced leukemogenesis. Mol Cell Biol 21(16): 5678-5687, 2001. PMID: 11463848. DOI: 10.1128/MCB.21.16.56785687.2001

68 Chan AKN and Chen CW: Rewiring the epigenetic networks in MLL-rearranged leukemias: Epigenetic dysregulation and pharmacological interventions. Front Cell Dev Biol 7: 81, 2019. PMID: 31157223. DOI: 10.3389/fcell.2019.00081

69 Marschalek R: The reciprocal world of MLL fusions: A personal view. Biochim Biophys Acta Gene Regul Mech 1863(7): 194547, 2020. PMID: 32294539. DOI: 10.1016/j.bbagrm.2020.194547

70 Bursen A, Schwabe K, Ruster B, Henschler R, Ruthardt M, Dingermann $\mathrm{T}$ and Marschalek R: The AF4.MLL fusion protein is capable of inducing ALL in mice without requirement of MLL.AF4. Blood 115(17): 3570-3579, 2010. PMID: 20194896. DOI: 10.1182/blood-2009-06-229542

71 Prieto C, Marschalek R, Kuhn A, Bursen A, Bueno C and Menendez P: The AF4-MLL fusion transiently augments multilineage hematopoietic engraftment but is not sufficient to initiate leukemia in cord blood CD34(+) cells. Oncotarget 8(47): 81936-81941, 2017. PMID: 29137234. DOI: 10.18632/oncotarget. 19567

72 Benedikt A, Baltruschat S, Scholz B, Bursen A, Arrey TN, Meyer B, Varagnolo L, Muller AM, Karas M, Dingermann T and Marschalek R: The leukemogenic AF4-MLL fusion protein causes $\mathrm{P}-\mathrm{TEFb}$ kinase activation and altered epigenetic signatures. Leukemia 25(1): 135-144, 2011. PMID: 21030982. DOI: 10.1038/leu.2010.249

73 Bursen A, Moritz S, Gaussmann A, Moritz S, Dingermann T and Marschalek R: Interaction of AF4 wild-type and AF4.MLL fusion protein with SIAH proteins: indication for $\mathrm{t}(4 ; 11)$ pathobiology? Oncogene 23(37): 6237-6249, 2004. PMID: 15221006. DOI: 10.1038/sj.onc.1207837

74 Ahmad K, Scholz B, Capelo R, Schweighofer I, Kahnt AS, Marschalek R and Steinhilber D: AF4 and AF4-MLL mediate transcriptional elongation of 5-lipoxygenase mRNA by 1, 25dihydroxyvitamin D3. Oncotarget 6(28): 25784-25800, 2015. PMID: 26329759. DOI: 10.18632/oncotarget.4703

75 Emerenciano M, Kowarz E, Karl K, de Almeida Lopes B, Scholz B, Bracharz S, Meyer C, Pombo-de-Oliveira MS and Marschalek R: Functional analysis of the two reciprocal fusion genes MLL-NEBL and NEBL-MLL reveal their oncogenic potential. Cancer Lett 332(1): 30-34, 2013. PMID: 23340173. DOI: $10.1016 /$ j.canlet.2012.12.023
76 Wachter K, Kowarz E and Marschalek R: Functional characterisation of different MLL fusion proteins by using inducible sleeping beauty vectors. Cancer Lett 352(2): 196-202, 2014. PMID: 25016062. DOI: 10.1016/j.canlet.2014.06.016

77 Kao YC, Lee JC, Zhang L, Sung YS, Swanson D, Hsieh TH, Liu YR, Agaram NP, Huang HY, Dickson BC and Antonescu CR: Recurrent YAP1 and KMT2A gene rearrangements in a subset of MUC4-negative sclerosing epithelioid fibrosarcoma. Am J Surg Pathol 44(3): 368-377, 2020. PMID: 31592798. DOI: 10.1097/PAS .0000000000001382

78 Massoth LR, Hung YP, Nardi V, Nielsen GP, Hasserjian RP, Louissaint A, Jr., Fisch AS, Deshpande V, Zukerberg LR, Lennerz JK, Selig M, Glomski K, Patel PJ, Williams KJ, Sokol ES, Alexander BM, Vergilio JA, Ross JS, Pavlick DC, Chebib I and Williams EA: Pan-sarcoma genomic analysis of KMT2A rearrangements reveals distinct subtypes defined by YAP1KMT2A-YAP1 and VIM-KMT2A fusions. Mod Pathol 33(11): 2307-2317, 2020. PMID: 32461620. DOI: 10.1038/s41379-020$0582-4$

79 Puls F, Agaimy A, Flucke U, Mentzel T, Sumathi VP, Ploegmakers M, Stoehr R, Kindblom LG, Hansson M, Sydow $\mathrm{S}$, Arbajian E and Mertens F: Recurrent fusions between YAP1 and KMT2A in morphologically distinct neoplasms within the spectrum of low-grade fibromyxoid sarcoma and sclerosing epithelioid fibrosarcoma. Am J Surg Pathol 44(5): 594-606, 2020. PMID: 31913156. DOI: 10.1097/PAS.0000000000001423

80 Yoshida A, Arai Y, Tanzawa Y, Wakai S, Hama N, Kawai A and Shibata T: KMT2A (MLL) fusions in aggressive sarcomas in young adults. Histopathology 75(4): 508-516, 2019. PMID: 31136005. DOI: $10.1111 /$ his.13926

81 Chen S, Dickson BC, Mohammed S, Aldape K, Swanson D, Coulombe J, Zakhari N, Karimi S, Nassiri F, Zadeh G, Mamatjan Y, Wang T, Lo B and Woulfe J: A dural-based spindle cell neoplasm characterized by a novel MN1-KMT2A fusion gene. Neuro Oncol 21(8): 1082-1083, 2019. PMID: 31095693. DOI: 10.1093/neuonc/noz091

82 Mitelman F, Johansson B and Mertens F: Mitelman database of chromosome aberrations and gene fusions in cancer. Available at: https://mitelmandatabase.isb-cgc.org/ [Last accessed on January 25, 2020]

83 Balgobind BV, Raimondi SC, Harbott J, Zimmermann M, Alonzo TA, Auvrignon A, Beverloo HB, Chang M, Creutzig U, Dworzak MN, Forestier E, Gibson B, Hasle H, Harrison CJ, Heerema NA, Kaspers GJ, Leszl A, Litvinko N, Nigro LL, Morimoto A, Perot C, Pieters R, Reinhardt D, Rubnitz JE, Smith FO, Stary J, Stasevich I, Strehl S, Taga T, Tomizawa D, Webb D, Zemanova Z, Zwaan CM and van den Heuvel-Eibrink MM: Novel prognostic subgroups in childhood 11q23/MLLrearranged acute myeloid leukemia: results of an international retrospective study. Blood 114(12): 2489-2496, 2009. PMID: 19528532. DOI: 10.1182/blood-2009-04-215152

Received November 28, 2020 Revised January 20, 2021 Accepted January 25, 2021 